Lee, K., Choi, H., \& Cho, Y. (in press). Becoming a competent self: A developmental process of adult distance learning. Internet and Higher Education. https://doi.org/10.1016/j.iheduc.2018.12.001

\title{
Becoming a competent self: A developmental process of adult distance learning
}

In this article, we aim to provide a developmental approach to understanding adult students' learning experiences of undertaking university-level study to completion at an open university, by employing a notion of "becoming". With the rapid growth of a number of online course offerings, there are an increasing number of adult learners entering or returning to universities. Despite the growing number of non-traditional adult students in online higher education, little is known about the dynamic processes of adult distance learning, through which adult students struggle to develop their learning ability, to balance their life and study, and to become self-regulated learners - ultimately competent selves and lifelong learners. Therefore, this article describes ten adult students' learning experiences from their enrolment in a distance programme to their completion of the programme many years later and deconstructs common assumptions of adult distance learners: namely, that they are a homogenous group with intrinsic and static characteristics that spring from their adultness or matureness.

Key words: Adult students; online higher education; adult distance learning; self-regulated learning; learning as becoming

\section{Introduction}

In this article, we will investigate experiences of a very selective group of distance learners — adult students pursuing an undergraduate degree at an open university, while consciously balancing their studies with other work- or family-related commitments. The rapid growth of a number of online course offerings along with an increasing educational use of information and communication technologies in higher education (Allen \& Seaman, 2015) has opened up a wider range of possibilities for adult learners to enter or return to universities (Ilgaz \& Gülbahar, 2015). While the increased accessibility of university education has been celebrated on the grounds of that large number of students have enrolled in those online courses (Lee, 2017), there have also been conflicting research outcomes. Those outcomes demonstrate somewhat disappointing realities of distance education (DE), including a high drop-out rate among adult students in open universities (see Carnoy, et al., 2012; Choi, et al., 2013).

Given this conflicting evidence regarding the realities for adult students in DE, it has been argued that, although adult students tend to be more independent and self-regulated in their learning, they also face more challenges than young students when studying at a distance (Hashim, Ahmad, \& Esa, 2011). That is, despite the fact that the "distance" provision of educational opportunities allows adult learners to begin their study in the first place, a large number of adult students might not be able to complete their study - due to other external factors, such as life commitments and unfamiliarity with new technology-mediated learning environments. In this context, previous studies on "adult students in open universities" have had two divided foci: i) on distinctive characteristics of adult students and instructional approaches suitable for them and ii) on adult students' motivation to enrol in DE programmes and the range of factors influencing their learning persistence (or, conversely, their drop-out).

Consequently, based on assumptions that the learning experiences of adult students (or non-traditional students) are fundamentally different from the experiences of young students (or traditional students), much research effort has been directed to identifying those factors that discriminate between those adult students who complete and those who dropout from DE programmes. Lee, Choi, and Kim (2013), for example, conclude that persistent adult students had higher levels of an academic locus of control $^{1}$, as well as a wider range of self-regulation skills. What studies of this nature risk, however, is assuming that adult students in DE are a single homogenous

\footnotetext{
${ }^{1}$ Academic locus of control refers to a particular personality trait that how an individual perceives the degree to which he or she controls other events or outcomes in educational settings (See more in Levy, 2007).
} 
Lee, K., Choi, H., \& Cho, Y. (in press). Becoming a competent self: A developmental process of adult distance learning. Internet and Higher Education. https://doi.org/10.1016/j.iheduc.2018.12.001

group with natural or intrinsic characteristics that spring from their adultness or matureness; and that will differentially determine their outcomes in DE contexts. Those studies arbitrarily define individual adult students as either completers or dropouts, whose destiny may be pre-determined — or at least predictable — by particular abilities; positioning those abilities as somewhat fixed and independent from external factors. These approaches, we argue here, are unable to effectively capture the developmental nature of learning.

What we try to avoid in this article, therefore, is to provide another static account of adult students, which seems to offer very restricted possibilities for making positive "changes" in adult students' learning experiences or "processes". Instead, we aim to provide a developmental approach to investigating adult students' learning experiences of undertaking university-level study to completion at an open university, by employing a notion of "becoming". Doing so will shed light on the dynamic processes through which adult students struggle to develop their learning ability, to balance their life and study, and to become self-regulated learners and ultimately competent selves. Adopting such a position has implications for our methodology. We are at pains not to arbitrarily classify students' experiences according to our own pre-selected notions of success or failure, which would devalue their voices by demoting them to being passive research subject whose voices are simply treated as research data. Instead, in this article, our adult student participants are viewed as legitimate, empowered agents - who are able to critically reflect on their own experiences, and who have the intellectual capacity to articulate the meanings of success or failure based on their own experiences.

Two research questions set out in our inquiry are:

1. What are the learning experiences of adult students who have undertaken their study to completion at an open university?

2. What meaningful changes in their learning experiences and perceptions occur over the time period during which they complete their study at the open university?

The following two sections will present the current state of knowledge about adult students in DE and their learning experiences; and identify gaps in that knowledge — gaps that serve as the location for the present study.

\section{Adult students in distance education}

A number of studies that have aimed to identify distinctive characteristics of adult students and their distance learning have been influenced by andragogical claims about how adults learn differently from children (see Brookfield, 1986; Jarvis, 2012; Knowles, 1985; Merriam, 2001).

For example, Cercone (2008) examines the characteristics of adult students and provides a comprehensive set of specific recommendations for online course design for adult learners. To construct a more accurate and detailed description of how those characteristics influence their online learning experiences, Cercone reviews four different adult learning theories including andragogy and self-regulated learning theory. Some of the identified characteristics of adult students and the related design recommendations are: "Adults may have some limitations [multiple responsibilities, biological conditions, technological difficulties] and these should be considered in the design of the online environment" (p. 140); "Learning styles need to be considered. In any group of adults there will be a wide range of individual differences, thus the individualization of learning experiences is important in many situations" (p. 141); "Adults need to be actively involved in the learning process" (p. 154); and "Adults need the instructor acting as a facilitator" (p. 156). Cercone concludes that adult students need to be considered as a whole person - more than a processor of information — with diverse personal, emotional, historical, and educational traits. In addition, adult learning processes involves:

The learning process involves learning about oneself and transforming not just what one learns, but also the way in which one learns. It is also about sensing, visualizing, perceiving, and learning informally with others. Interaction and collaboration should occur in the learning environment to facilitate adult learning (p. 151). 
Lee, K., Choi, H., \& Cho, Y. (in press). Becoming a competent self: A developmental process of adult distance learning. Internet and Higher Education. https://doi.org/10.1016/j.iheduc.2018.12.001

Gravani (2015) also stresses personality, mutuality, emotionality, and formality as four dimensions influencing adult learning processes in a DE context. The first dimension, 'personality', refers to the fact that each adult student comes to the DE programme with his or her own "cultural baggage" (p. 189), including unique past experiences, needs, interests, learning styles: so, Gravani argues, one-size-fits-all principles will not work for this group. The second dimension, 'mutuality', corresponds to the andragogical principles of self-directed learning, which proposes that adults "should have control over their own learning and [that] course content should be designed mutually by providers and learners" (Gravani, 2015, p. 189). The third dimension, 'emotionality', emphasises the importance of emotional understanding for adult students to be successful in their learning. It is suggested that adult students in DE settings tend to seek opportunities to share their emotions with their tutors and peers, and discussion of this emotionality dimension highlights that it is critical for them to feel respected and trusted. The final dimension, 'formality', is closely related to recommendations that the course design should seek to provide individual adult students with 'multiple choices' — of a range of learning activities and methods that collectively respond to aspects of their unique personality.

Overall, the conclusions of Gravani's (2015) study are constructed to serve the argument that adult students' distance learning needs to be "more open, flexible, mutual, variable, active and autonomous" (p. 191). Hermans and colleagues (2013) at the Open University of the Netherlands similarly suggest that educational institutions need to develop more flexible online courses, to meet a growing demand for learning among adult learners whose needs and interests are varied. Hermans and colleagues (2015) subsequently proposes a model to provide various target groups with different access levels and a range of distinct learning activities, all within a single course. Makoe, Richardson, and Price (2008) also seek to demonstrate that adult students at the Open University in the United Kingdom hold distinctive conceptions of learning that are culturally and contextually dependent; they draw similar conclusions.

While this literature concerning the characteristics of adult learners continues to offer different, rather normative and prescriptive, design principles; adults' distance learning processes in real-life settings seem so much more challenging and complex. Another prominent strand of research (e.g., Guri-Rosenblit, 2009; Sáiz, 2009; Toon et al., 2009) points out that a large number of adult learners studying at a distance face continuous challenges and experience emotional frustration due to their lack of self-regulated learning skills. Perhaps importantly, it is suggested that this problem particularly affects those learners from disadvantaged backgrounds. Toon and colleagues (2009), for example, concludes that a self-study model in DE settings only suits those highly motivated students who have clear and practical goals, such as earning industry-based certifications. In this 'andragogy-sceptic' literature, the high drop-out rates among distance students at open universities, including adult ones, are taken as indicating a clear disconnect between andragogical claims about adult learning and the actual experiences of adult learners studying at a distance from their teacher (see Choi, et al., 2013; Lee \& Choi, 2013; Levy, 2007). A more detailed discussion about the drop-out phenomenon will be presented in the following section.

Other research reaches similar conclusions from rather different argumentation. Joo's (2014a; 2014b) works, for example, reveal the complex and multi-level contradictions existing between aspects of adult learners' personal lives, the institutional offerings of DE universities, and the broader societies to which both learners and institutions belong and with which they interact. By illustrating the vulnerability of adult learners as social and cultural beings strongly influenced (though not controlled) by external factors, Joo's works effectively challenge some of the artificially-drawn distinctions between children as non-autonomous beings and adults as autonomous beings. Interestingly, given the research site for the present work, Joo's study mainly focuses on the experiences of educational exclusion and social alienation of adult learners at the Korea National Open University.

\section{Motivation and Drop-out}

The other prevailing theme in the currently published literature on adult students in DE concerns two closely related matters: adult students' motivation to enrol in DE programmes; and different factors influencing their learning persistence (or their reasons for dropping-out). 
Lee, K., Choi, H., \& Cho, Y. (in press). Becoming a competent self: A developmental process of adult distance learning. Internet and Higher Education. https://doi.org/10.1016/j.iheduc.2018.12.001

One of the most salient discourses about adult students in DE contexts highlights how they seek to gain 'second opportunities' to access university education (Brändle, 2016; Joo, 2013a; Joo, 2014b; May \& Bunn, 2015; Nair $\&$ Hindle, 2016). That is, a large number of researchers portray adults enrolling in open universities as nontraditional students who have missed out on earlier opportunities to attend traditional campus-based universities: often because of the limitations of the social, cultural, or economic capital that they or their family possessed (Brändle, 2016). This view of adult learners' participation in DE is in line with a more general perspective on online higher education: that it is open and accessible to the disadvantaged (see Lee, 2017). These studies all suggest that this older group of students, who have 'other' social responsibilities (as working adults, mothers, soldiers, etc.), have strong aspirations for pursuing their university degrees. It is suggested, furthermore, that these students are highly motivated to study and to optimise their second opportunities: even when earning the degree provides little in the way of economic benefits (Castaño-Muñox, Carnoy, \& Duart, 2016; Carnoy et al., 2012). There have also been studies investigating adult learners' self-reported needs for participation in DE in more specific terms: Raghavan and Kumar (2007), for example, report that the most prevalent need among adult learners at the Open University Malaysia is for professional advancement, followed by cognitive interest and communication improvement, while the least prevalently identified needs related to aspects of escapism and social stimulation; Mulenga and Liang (2008), similarly, report that the strongest motivational factors underlying older adults' participation in DE are related to intellectual stimulation, keeping up, fulfilment, and adjustment, whereas the least important factors are related to escape or social contact.

Despite these reports of strong motivation for university-level study among adult learners, another set of literature prominently indicates that it is challenge for adult students to maintain their initial levels of motivation and to pursue and complete their distance studies. For example, Choi and colleagues' (2013) analysis of different reasons for students' non re-enrolment at Korean National Open University indicates that the strongest reason concerns heavy workloads in the main place of work (64.3\%): that reason is, it is suggested, much more prevalent than any institution-related variables such as dissatisfaction with tutors' feedback on their submissions. Choi and colleagues' article also suggests that, although adults (and particularly women) initially perceive their enrolment in DE programmes as an opportunity to pursue their study while overcoming immediate socioeconomic barriers and balancing family and study commitments, family and work responsibilities tend to remain a major and unsettled obstacle to their successful completion of the programmes. Similar studies that focus on adult student drop-out consistently suggest that a lack of time for studying (Carnoy, et al., 2012) and a failure to balance academic workload with other life obligations (Vergidis \& Panagiotakopoulos, 2002) as the more important factors underlying low completion rates.

On the other hand, it is noticeable that previous studies have rarely focused on how adult students do successfully complete their study (with a few exceptions: e.g., Castles, 2004; Kember \& Leung, 2004; Lee \& Choi, 2013). For example, another study in Korean National Open University (Lee \& Choi, 2013) reported a strong relationship between students' internal academic locus of control and retention; and also between students' satisfaction and retention. That satisfaction level is also strongly related to students' 'flow experiences', by which is meant the experience of being fully immersed in learning activities with a feeling of engagement and enjoyment in the processes. Flow experiences seem largely influenced by students' choice of learning strategies: therefore, Lee and Choi suggest that students' own perceptions of self-control over their learning activities and choices of learning strategies that enable them to be immersed in their learning processes are two of the most critical factors influencing adult learners' learning persistence. Kember and Leung (2004) report findings in keeping with these views: they suggest that part-time students are more likely to complete their study where they effectively negotiate times to study with their family; establish regular study routines; 'earn' high levels of social support; and perceive themselves to have high personal self-determination.

Although the currently available literature provides meaningful insights about the factors that influence adult learners' learning persistence and dropping-out of DE programmes; those quantitative studies tend to disregard the diversity in adult learners and assume adult learners as a single homogeneous group and hence limit their discussions to drawing general patterns among adult learners. Consequently, it has remained unknown how individual adults enrolled in open universities navigate and negotiate multiple commitments in their lives; select 
Lee, K., Choi, H., \& Cho, Y. (in press). Becoming a competent self: A developmental process of adult distance learning. Internet and Higher Education. https://doi.org/10.1016/j.iheduc.2018.12.001

and establish suitable learning strategies and routines; and handle and overcome different challenges faced throughout their study: that is, we have not yet developed a comprehensive understanding of how adult learners successfully complete their degree at open universities and what types of pedagogical support effectively facilitate adult learners' learning processes and outcomes. The ultimate aim of this study is to better understand adult students' experiences of undertaking university-level study to completion at an open university, based on a motivation to further support this particular group of students more effectively in the future.

\section{Methodology}

This qualitative study employs a grounded theory approach to understand and explain adult students' experiences of completing their study as distance learners. Grounded theory methodology (Charmaz, 2014; Glaser, \& Strauss 1967; Urquhart 2013) focuses on generating knowledge and constructing theoretical claims in an inductive way: that is, researchers employing this approach take as their departure point the collection of data; they then allow that data to speak and to guide their subsequent inquiry. Thus, an outcome of the inquiry (i.e., a 'theory') tends to be thoroughly drawn from the data (i.e., it is 'grounded' in it).

Our target population group was adult students who had completed their university-level study (including those expecting to earn their degree at the point when this study was conducted) at the Korean National Open University (KNOU). KNOU, the first national DE institution, has performed a major role in adult education in Korea since its establishment in 1972. As of 2016, it consists of 4 Colleges and 22 Departments, has more than 120,000 students in current enrolment. Typically, approximately $35 \%$ of enrolled students drop out of their studies. The average age of students is $43.3: 10 \mathrm{~s}(0.6 \%)-20 \mathrm{~s}(18.9 \%)-30 \mathrm{~s}(25.6 \%)-40 \mathrm{~s}(34.0 \%)-50 \mathrm{~s}$ $(15.8 \%)-60 \mathrm{~s}(4.5 \%)$ - over $70 \mathrm{~s}(0.6 \%) .78 .1 \%$ of the students are adults with occupations. Most students take 5 courses per term and assessment consists of $70 \%$ of final exam and $30 \%$ of lecture attendance or online assignment - to pass the courses, students are expected to receive a grade of 70 or above. The total number of 24,424 students graduated in 2014 .

Among those graduates, we selected about two hundred students who had been categorized by a previous study as being members of an adult student group with a higher risk of dropping out than the others and sent them an email invitation to take part in a one-to-one interview about their academic experiences at KNOU. The previous study on academic achievement of adult students, conducted by our colleagues at KNOU (Jung et al., 2013), identified two at-risk student groups: i) male employees (including civil workers) in their 30s and 40s and ii) female employees in their 20s and 30s. A purposeful sampling method was used to select these participants on the grounds that they were expected to be "information rich" (Patton, 1999, p. 169); this was done in order to develop a detailed understanding of the experiences of completing students at KNOU. The careful decision to select this particular group of students was made based on the ground that it can be more meaningful to listen to those at-risk students' successful completion experiences.

Ten students agreed to take part in the study: approximately, $5 \%$ of the invited students who either graduated in 2013 or were in their final term, expecting to finish in 2014 - the same year when the study was conducted. The participant group consists of five male students and five female students from eight different programmes - thus, it was assumed that we could draw out "multiple" perspectives and "diverse" voices within the sample group. But, at the same time, the participant can all be categorized as students with a higher risk of dropping out on the bases of: i) their biological age (male in 30s-40s and female in 30s) and ii) their social status (all employed either by a private company or by a government organization). Many of these students were also parents (see Table 1). Each semi-structured interview, guided by twelve open-ended questions, was conducted at a place and time convenient to each participant and lasted between 1 hour and 1.5 hours. The questions were designed to guide each participant to effectively recollect their memories and to talk about their experiences at KNOU in chronological order (from the first semester to the last one). The sample interview questions included: "could you please tell me about your first semester at KNOU? How did you feel back then?" and "Do you remember how everything was when you started your second semester?" The questions also focused on particular academic challenges faced by the students in different stages of their study and the strategies that they had developed to overcome those challenges and to successfully complete their study. Follow-up interviews were 
Lee, K., Choi, H., \& Cho, Y. (in press). Becoming a competent self: A developmental process of adult distance learning. Internet and Higher Education. https://doi.org/10.1016/j.iheduc.2018.12.001

conducted by email exchange, where necessary to clarify points made by the participants and/or to gather more details to support the ongoing process of data analysis. This is in keeping with the inductive approach characteristic of grounded theory methodology.

Table 1.

Interview Participants

\begin{tabular}{|c|l|l|l|l|l|l|l|l|}
\hline Participant & $\begin{array}{l}\text { Admission/ } \\
\text { Re-admission }\end{array}$ & Age & Gender & $\begin{array}{l}\text { Leave of } \\
\text { absence }\end{array}$ & Programme & $\begin{array}{l}\text { Status in } \\
2013\end{array}$ & $\begin{array}{l}\text { Previous } \\
\text { Education }\end{array}$ & $\begin{array}{l}\text { Other } \\
\text { Commitments }\end{array}$ \\
\hline A & $1994 / 2012$ & 46 & M & 20 semesters & English & Graduated & College & $\begin{array}{l}\text { Full-time work } \\
\text { Married/2 Children }\end{array}$ \\
\hline B & 1999 & 38 & F & 13 semesters & Management & Graduated & High School & $\begin{array}{l}\text { Full-time work } \\
\text { Married/4 Children }\end{array}$ \\
\hline C & 2006 & 40 & M & 10 semesters & Economics & Expecting & College & $\begin{array}{l}\text { Full-time work } \\
\text { Single }\end{array}$ \\
\hline D & $2007 / 2010$ & 35 & F & 11 semesters & $\begin{array}{l}\text { Home } \\
\text { Economics }\end{array}$ & Graduated & College & $\begin{array}{l}\text { Full-time work } \\
\text { Single }\end{array}$ \\
\hline E & $2007 / 2010$ & 40 & M & None & $\begin{array}{l}\text { Computer } \\
\text { Sciences }\end{array}$ & Expecting & College & $\begin{array}{l}\text { Full-time work } \\
\text { Married/2 Children }\end{array}$ \\
\hline F & 2007 & 30 & F & 5 semesters & Japanese & Graduated & High School & $\begin{array}{l}\text { Full-time work } \\
\text { Single }\end{array}$ \\
\hline G & 2007 & 43 & M & 3 semesters & Korean & Graduated & High School & $\begin{array}{l}\text { Full-time work } \\
\text { Single }\end{array}$ \\
\hline H & 2008 & 34 & F & 5 semesters & Management & Expecting & College & $\begin{array}{l}\text { Part-time work } \\
\text { Married/1 Child }\end{array}$ \\
\hline I & 2009 & 47 & M & 6 semesters & $\begin{array}{l}\text { Agricultural } \\
\text { Studies }\end{array}$ & Graduated & University & $\begin{array}{l}\text { Full-time work } \\
\text { Married/2 Children }\end{array}$ \\
\hline J & $2009 / 2010$ & 30 & F & 6 semesters & Korean & Graduated & College & $\begin{array}{l}\text { Full-time work } \\
\text { Single }\end{array}$ \\
\hline
\end{tabular}

All audio-recorded interview files were transcribed and analysed to construct a developmental (not static) understanding of adult students' distance learning experiences as a process of "becoming" a competent self (i.e., an independent life-long learner). The initial coding was done by the first author, following the guidelines suggested by Strauss and Corbin $(1990 ; 2015)$ that suggest three steps of open coding, axial coding, and selective coding. The transcribed text was broken down as a series of meaning units of analysis (i.e., sentences, paragraphs) and those units were carefully coded. The initial codes were identified and named by highlighting meaningful phases on the printed interview transcripts and making notes of potential categories emerging from the highlighted parts on the margins of the transcripts. The codes are more carefully examined and compared with/against each other; and further conceptualised as independent categories (i.e., open coding: 27 codes and 13 categories were identified here). Then, the second round of reading was undertaken to develop the open coding results further and find relevant links and relationships among identified categories and codes. The connections between those categories were thought through using the two conceptual notions of "becoming" and "the self" and initial categories were chronologically sorted and logically grouped by selecting common ideas emerged across the 10 interviews (i.e., axial coding). This coding exercise was assisted by using Microsoft Excel and 6, more substantial, categories were generated as a result. Those six categories are as follows: i) easy admission; ii) initial struggles in an entirely new, peculiar, educational system; iii) running away from the system and returning to the system; iv) trial-and-error as a lone learner and set up the habits; v) strong resistance to any disruptions, and vi) being and feeling competent and proud.

The categories, with the associated data set, were shared with the other two authors for the purpose of memberchecking; subsequently, the three authors had a meeting to develop more accurate representations of the participants' voices and the features of the investigated phenomena, and so to produce more "valid" theoretical claims. The final round of reading was undertaken by moving back and forth between the original interview transcripts and the excel sheets. Subsequently, the four themes, presented in the present paper, were drawn from the categories as a result of our meeting (i.e., selective coding). The first author, who is also a tutor teaching on a 
Lee, K., Choi, H., \& Cho, Y. (in press). Becoming a competent self: A developmental process of adult distance learning. Internet and Higher Education. https://doi.org/10.1016/j.iheduc.2018.12.001

distance programme, wrote a draft of this article and invited two of her more experienced colleagues teaching on the same distance programme to ace as "critical friends", whose role was to read and provide comprehensive feedback on the claims made by the authors, thereby enhancing the "trustworthiness" of the research outcomes (Lincoln \& Guba, 1985). Lastly, the final claims were compared with/against other existing claims in the relevant literature to ensure both its trustworthiness and its theoretical contribution to the current body of knowledge about the adult distance learners and their experiences at open universities.

\section{Results}

In this section, we will present four themes emerging from our data analysis, namely: 1) Doing the first semester, 2) Becoming a self-regulated learner, 3) Staying calm and carrying on, and 4) Becoming a competent self Those four themes are respectively connected to different phases of the learning journeys that our student participants have undertaken: from their enrolment in a distance programme at KNOU to their completion of the programme many years later. This is closely related to the central aim of this study, which is to provide a developmental narrative about adult distance learning. The themes are also named by borrowing phrases from the interviews to give a real voice to the adult distance learners and to capture a real sense of them managing to persist and complete their distance learning.

\subsection{Doing the first semester: "It was a real struggle... felt like Alice in Wonderland"}

The first (and the most salient) theme, discussed by all 10 interviewees, concerns adult students' experiences during their very first semester at KNOU. All of the participants mention that entering KNOU is extremely easy. That is, this "second" (or sometimes, third) opportunity to access the university education is rather readily given to these adults, thanks to a relatively low level of entrance requirements and remarkably cheap tuition fees.

Of course, in terms of the tuition fees of KNOU, it is not a big deal. In fact, it would be 100,000 won [70 GBP] that I may have to spend each month if I learn English from any private institution, 600,000 won for 6 months, then. Here, the KONU tuition is only 3 or 400,000 won for a semester. Money is not an issue. (Participant A)

However, actually taking up and taking advantage of the opportunity is extremely difficult during the first semester, and most participants describe how they "did not expect doing a university study to be this much difficult". (Participant C). In fact, three of the ten participants had dropped out from the university after the very first semester (Participant A in 1994; D in 2007; and J in 2009). They then returned to the university several years later to resume their studies mainly because they did not have any other, better or cheaper, options (readmission: Participant A in 2012; D in 2010; and J in 2010). Three other students (Participant E, I, F) also took time off after their first semester for similar reasons: being shocked by i) the massive amount of work to do and ii) an entirely new ("incomprehensible" or "puzzling") learning system. Participant $\mathrm{C}$ effectively describes how "to complete the first semester is, in fact, an unofficial entrance examination to the university and $98 \%$ of the adult students give up and drop out after their final exam that most of them get several Fs anyway!"

Participant F recalls her first semester by strongly saying "it was a real struggle... felt like I was Alice in Wonderland" and describes a high level of uncertainty and anxiety during that semester, which made her decide to take time off from her study:

I did not know anything when I was a freshman here: totally confused. After all, I failed one course, and didn't know what to do. And then suddenly was in the second term again. At that time, I didn't have any knowledge about university and its system - it was even so difficult to sign up for courses. (Participant F)

Participant E is the only student in this study who earned a university degree (in Law) from KNOU in 2009 without taking a break since first enrolling on the programme in 2007. He then describes starting another degree programme (in Computer Sciences) in 2010 and enthuses about the fact that, at the time of the interview in 2013, he is in the last semester of his second programme. Yet, despite his seemingly successful and satisfactory 
Lee, K., Choi, H., \& Cho, Y. (in press). Becoming a competent self: A developmental process of adult distance learning. Internet and Higher Education. https://doi.org/10.1016/j.iheduc.2018.12.001

academic journey, his recollection of his very first semester in 2007 is not any better than other participants'.

The very first semester was a mess - a real mess. The most challenging part at KNOU is the first semester. Was not familiar with the university system and did not know what and how to study, however, it did not wait for you. Boom! Suddenly exam time. On the mid-term exams, I was just in a shock and again suddenly final. Three exams a day and needed to prepare for six exams... I did not have any strategies and so was just up all night studying really hard... [but] lots of Fs. (Participant E)

The high level of anxiety and uncertainty, which all interviewees in this study similarly describe experiencing during their first semester, tend to be mainly attributed to their lack of understandings about university systems and procedures (e.g., how to choose and register for courses and change and drop the courses). In campus-based university contexts it seems plausible to suppose that this type of "tacit knowledge" about "what I am supposed to do after getting into the university" (Participant J) is likely to be obtained through socialisation with other students in the same cohort, or else to be passed on to new students by senior students in the same programme.

However, adult students at KNOU tend to remain alone and unable to understand what and how to do things right at the university. In addition, all participants express carrying vague preconceptions, clearly not borne out by the reality, about the 'easy' nature of distance learning: such that earning a university degree from DE programmes would be much easier and less demanding than getting a degree from traditional campus-based universities. This false conception seems closely linked to the relatively open access that is provided to university education: however, as Participant $\mathrm{C}$ describes, "entering university was simple but becoming [living as] a university student" was not. Such a huge gap between what our participants recall expecting (and perhaps more precisely, imagining) before and what they actually experienced after getting into KNOU, almost makes open university as an ambiguous place like Wonderland: from outside, it is imagined as a land of opportunities and promises but from inside, it seems a land of struggles and uncertainties.

\subsection{Becoming a self-regulated learner: "It is the 'must'. You have to find your own way of studying."}

The second theme represents some of the shared aspects of learning practices that our interview participants have established for themselves, by various processes of "trial and error" (Participant E), in their first year - and that they then repeat throughout the rest of their learning journey. It is particularly noticeable that eight out of the ten participants mention that they spend (or strive to spend) one hour a day on their study: six of them start their day really early, between 4am and 6am, in order to secure one hour to study early in the morning, while two of them accomplish something similar late at night, after coming home from work and putting their children in bed. Four participants emphasise in their accounts the great importance of "using any spare time during the day to study little by little, not to be overwhelmed during stressful exam weeks" (Participant B). Most participants seem to spend these study hours during their days specifically listening to online lectures for the purpose of becoming familiar with learning content: watching video lectures on their smartphones while on the tube or bus in their commuting time, for example, seems a quite common practice among the adult learners at KNOU.

Every morning, I wake my children up. I have three in primary school and one in preschool. I drive them to schools and go to work. I stay at my office until 6 and then come home. Need to prepare for dinner and feed my children and help their homework. After doing some housework after they go to bed and then it is usually 11 o'clock. Honestly, I really do not have time for study unless I wake up in the early morning at 5 . So, I work up at 5 and study for an hour or two. (Participant B)

Participant A and F, unlike the other 8 students who recalled establishing everyday study practices, describe their learning approach. Participant A (male, 40s, married with 2 children) has a full-time job with irregular work schedules, while Participant F (female, 30s, single) has a full-time job and active social circles: both of them therefore find it difficult, if not impossible, to study every day. Thus, Participant A spends 6 or 7 hours on 
Lee, K., Choi, H., \& Cho, Y. (in press). Becoming a competent self: A developmental process of adult distance learning. Internet and Higher Education. https://doi.org/10.1016/j.iheduc.2018.12.001

weekends "catching-up" on his study and online lectures, and Participant F has also developed a specific study strategy that involves concentrating on a number of major "deadlines" and "dates" in her courses, such as assignment submission deadlines and final exam dates. When those deadlines are approaching, she takes a few days off and studies intensively to meet the course requirements. Participant A says, "Hmmm... it is the "must". You have to find your own way of studying. It is unavoidable to try harder and focus more since we have two things in our life: work and study. Nothing is free - we know."

Therefore, we argue, it seems that those adult students who are able to complete their study at KNOU, despite their other commitments creating ongoing obstacles, are able to do so by developing a unique lifestyle including useful habits: as Participant H recalls, "one day, I found that my extremely busy days become very simple and almost peaceful" and then "I repeat the simple day again and again and go with the flow, the rhythm." That is, enrolling in the university is relatively easy; however, the actually meaningful learning opportunity seems to be given only to those who can position themselves as an "self-regulated" (or "independent") learners, managing their own learning practices accordingly.

Another important, and related, point put forward by most of our participants is that, along with setting up the right routines for their living conditions, it is necessary to learn or "earn" know-hows (i.e., tacit knowledge and appropriate strategies) for being successful at KNOU. Unlike the 'habits', which vary among adult students according to their life contexts, this set of 'know-hows' tends to be perceived as transferrable and rather universal. That includes, for example, knowledge about where to find exam preparation materials; how to save time by watching online lectures at higher playback speeds; how to prepare for final exams; what to study on the night before the exams; what to do when feeling demotivated; and what to do when in receipt of poor grades. These know-hows seem to be critical for a lone learner, but difficult to acquire as a lone leaner. Many of our participants refer to specific people as a source of their know-how(s): in many cases, close friends, colleagues, or family members who previously studied at KNOU. Several participants also mention particular students and graduates of KNOU (who they have never met in person) whose study strategies and success stories have been shared via media such as university newspapers or university websites. Furthermore, it is suggested by a number of interviewees that if they knew some of those know-hows in the first year, they could have established their study habits faster and more effectively: that is, they could have accelerated the trial and error process.

\subsection{Staying calm and carrying on: "Doing alone. I found it convenient."}

The third theme covers the period after becoming a self-regulated learner — where the interview participants successfully set up and got used to the particular lifestyle of adult students at KNOU. Despite the extent of the variation among the adult students, this relatively stable and long period generally is described as extending from the third (or fourth) semester to the end of their study. Participant J, for example, was in her sixth semester since her return to KNOU in 2010, whereas Participant C was doing his thirteenth semester since his first enrolment in 2006 when the interviews were conducted:

I took a long time since I have been doing only one or two courses per semester... [In the first semester] received F and I felt so unmotivated and annoyed. Next semester, I did only one course and received 90 . I got 29 out of 30 on my mid-term report and I missed only 9 points from my final exam - only three wrong answers! It was possible only because I did one. So, since then, I have been a part-time student paying only for two courses that I sign up: so it is just 120,000 won ( 83 GBP). Even cheaper and I can be more relaxed. (Participant C)

As suggested by the interview excerpt above, the pace and time taken by the adult students to complete their degree programmes is extremely diverse; although for obvious reasons those adult students doing their study as part-timers generally took much longer time to earn their degree if compared to more traditional groups of fulltime students. Regardless of the length of their studies, all interview participants report experiencing this period of their study at KNOU very positively: Participant $\mathrm{H}$ even refers to the period as "peaceful". Although still facing difficult moments over which they had little control, most participants report feeling that their life is 
Lee, K., Choi, H., \& Cho, Y. (in press). Becoming a competent self: A developmental process of adult distance learning. Internet and Higher Education. https://doi.org/10.1016/j.iheduc.2018.12.001

generally under control during this period, and that they come to find (many aspects of) their study interesting and "fun". So long as they do not have any major life changes or challenges (e.g., pregnancy, changing job, the death of a family member) to interrupt or break their "rhythm" of studying part-time, participants expressed a sense of confidence about this period of studying - a feeling of confidence that they will continue and enjoy their study at KNOU.

It is so much fun! When I was a college student years ago, entire study was focused on how to earn certificates and get a job. Now, I do not worry about those things and just study humanities or liberal arts - feeling like learning real knowledge. Read Freud's book and Marx's the Capital. Of course, all for writing reports, but I found it really fun. (Participant C)

One of the most notable findings is that adult students tend to find it very discouraging and/or confusing when an enrolled course falls off the standard structure and format (e.g., the online lectures-assignments-exams sequence) - to the extent that they find it almost impossible to continue or complete the course. All interviewees emphasise in their accounts that they do not need much flexibility in choices about pedagogical activities or content; and, indeed, that they prefer having the same standardised structure across all the courses at KNOU. This preference seems related to the habits and know-hows they have constructed, which to a great extent anticipate and rely on those standardised structures ${ }^{2}$.

In the same vein, eight of ten interview participants describe learning as an individual and personal activity. Even though most participants reported finding "doing alone" and "being alone" very challenging at the beginning of their study (in fact, as discussed earlier, many of them believe it is essential to earn know-hows from more experienced learners), they believe that once they established their own learning habits, they feel it unnecessarily to interact with other learners. A couple of them even emphasise in their accounts that "It is a waste of time. I am not doing this [study] for socialisation" and "It is too much inconvenience for little gain" to study with others (Participant C and I). Even the two students who are relatively positive about studying with others (Participant $\mathrm{G}$ and $\mathrm{H}$ ) actually focus in their accounts on sharing information (e.g., exam dates) and resources (e.g., summary notes), rather than co-constructing knowledge or having more 'academic' discussions.

When it comes to having one-on-one interactions with tutors, respondents report being aware of the opportunities that exist, yet most suggest that they find it unnecessary so long as the course structure is clear and the course expectations are clearly explained (in a course handbook or in a course environment). Instead, adult students tend to value the "good" video lectures - in which instructors' lecture styles are perceived as more personal and dialogic - and, similarly, study guidebooks where these are written in a conversational way, with instructors' personal stories, thoughts and experiences.

At the same time, however, participants report an urgent need to be more regularly and frequently contacted by university, with automatic SMS and emailing services being much preferred for this - especially in order to be reminded about deadlines and any changes made in relation to those dates. Participant $\mathrm{C}$ recounts the following experience when emphasising the importance of having an SMS alarming service:

At that time, I did not have enough energy even to turn on my computer after coming home from work. So I didn't check the announcement about the exam date change on the course website, well... so I missed the exam and failed.

They also report the need to be occasionally contacted by or connected with other adult students who are in life situations they perceive as similar to theirs. For example, Participant B, who is a mother of four children,

\footnotetext{
${ }^{2}$ It is worth noting an exception, however: six interviewees mention in their accounts that they wished the university exam system was more flexible - at the moment, all students need to physically attend the designated exam site and take an exam on the same day at the same time (usually Saturdays and Sundays), which is resented in some accounts.
} 
Lee, K., Choi, H., \& Cho, Y. (in press). Becoming a competent self: A developmental process of adult distance learning. Internet and Higher Education. https://doi.org/10.1016/j.iheduc.2018.12.001

recounts that whenever she feels "exhausted" and "depressed" after a long day of work, she visits an online community space (within the university website) and shares her emotions, feelings, and anecdotes; she finds many other mothers there who are just like her and receives enormously supportive messages from those other mothers in that space. According to the student these occasional "therapy sessions", mediated by an asynchronous communication tool, are the main factor that has stopped her "giving up". Another social aspect of adult learning at KNOU is closely related to making adult students stay motivated: a half of the interview participants in the study mentioned that it is always helpful to listen to other students' challenging but successful stories, or to see other motivated students. A few motivating cases mentioned by the participants include an old lady in her 70s diligently notetaking during face-to-face lectures; a middle-aged woman on her heels running into a lecture room after her long work hours in the evening; and a university news story about a former football player, who was kicked out of the field due to a severe injury in a story much covered by the popular media, becoming a lawyer after graduating from KNOU.

\subsection{Becoming a competent self: "I trust myself. I really can do this."}

Participant B recounts how she is, at the moment of her interview, about to earn her first university degree in Management - and that she is planning to start another university degree programme (English) at KNOU. Up until now Participant B had been studying at KNOU for 14 years (on and off), during which time she had intercalated four times whenever she was pregnant and gave birth to (and raised) her four children. The strongest motivation for her to return to the programme again and again is, she reports, that: "I just want to find myself. I do not want to just remain as someone's mother or someone's wife (laughing)." This middle-aged woman also shares her life goal: "I want to keep going and then continue my graduate studies, and become a mother who is inspiring and motivating to my children throughout my entire life." She adds: "It was not easy, really not and I know it will not be easy next time as well. However, I trust myself - I really can do this." That theme of "being a mother (a father) who is continuously studying and so inspiring" is very salient and specifically mentioned by every participant who is a parent. It seems like this is one point where their 'student' and 'parental' identities meet, with an attendant perception of synergy: that there is a supportive balance in their life and that what they are doing and what for they are struggling carries a powerful meaning.

Nine interview participants indicate that they are planning to enrol in another degree programme (either an undergraduate or graduate level programme). Although some accounts set forth more developed plans while some indicate a process of thinking through possibilities, it is very clear that all of them were confident in their ability to pursue and succeed despite upcoming challenges. Only one student indicates in their account some doubt about the accessibility of graduate programmes - and that is not because he feels not competent but instead because the tuition fees are much more expensive compared to those for the undergraduate programmes (Participant C). It is also clear that all of them were enjoying many aspects of their study and the current lifestyle, which they had set up and maintained over the past years for the purpose of completing their degree programmes. For example, one account mentions that "I feel I am addicted to studying" (Participant H), while another suggests that "I am bored and feeling somewhat empty after finishing my programme. I am also a bit afraid that I would become retarded if I do not continue" (Participant E).

Themes such as "feeling a sense of achievement" and "being proud of oneself" emerged repeatedly throughout our analysis. Such self-confidence seems to be further strengthened and developed where participants report receiving positive recognitions from others - including those close friends and colleagues who seem to understand and appreciate the persistence required to successfully complete and earn degrees from KNOU. Although it is true that many open universities, including KNOU, suffer from relatively low institutional rankings; that there is a prevailingly negative perception about the pedagogical quality of many DE programmes; and that there is a lack of social recognition of university degrees from open universities (see Joo, 2014a; 2014b), the accounts of participants do suggest that there is a high level of respect for those who have 'made it': "everyone who knows how hard it is to get a degree from KNOU, values this degree and I do. I am one of them" said Participant H.

Everyone knows at my workplace that it is extremely difficult to graduate from KNOU. 
Lee, K., Choi, H., \& Cho, Y. (in press). Becoming a competent self: A developmental process of adult distance learning. Internet and Higher Education. https://doi.org/10.1016/j.iheduc.2018.12.001

Everyone says it is incredible that I am almost completing it - showing a great respect for my persistence. Sometimes they call me "a man of persistence" or "a man of determination" often compared with those whom quit smoking cold turkey (laughing). (Participant C).

When it comes to the usefulness of knowledge that students report learning from KNOU, many accounts emphasise that the knowledge is not readily applicable in their life or work - nevertheless, it is worth noting that most of the interviewees pointed out that "university" education and particularly the liberal arts courses had broaden their perspectives and enhanced their understandings of the world, society, and themselves: "I become a better person" (Participant G). Another salient narrative coming from the interviewees suggests that it is a pleasure to become "a legitimate member" of certain social (or academic) communities. Participant E, who at the time of interview reports being about to earn his second degree in Computer Sciences (the first one was in Law), openly admits that the knowledge he is acquiring from the degree programmes is not directly relevant to his work-life; and, furthermore, that the two degrees per se do not provide him with any tangible and immediate benefits in his work (such as a pay raise or promotion). However, Participant E conveys much pride in himself as a member of the two academic fields which, he strongly believes, increased the overall value of him as a social being. Although this is not necessarily the outcomes that both open universities and adult students expect when they first enter university, we argue here that these positively perceived outcomes by students do need to be taken into account when the quality of university programmes and student learning experiences are evaluated.

\section{Discussion and Conclusion}

In this qualitative study, we explore and document ten adult students' experiences of undertaking universitylevel study to completion at KNOU, emphasising those experiences as dynamic developmental processes of becoming a competent self. The findings clearly demonstrate how these seemingly "successful" adult students have invariably experienced, since the time they simply walked into this new learning environment, constant struggles and difficulties. Those struggles and difficulties include their conscious development of their own learning ability, efforts to establish appropriate study habits and lifestyle suitable for their becoming a selfregulated learner - and, in addition, their management of many other aspects of their everyday life identity. To some extent our results do support some previous observations on adult learners in DE contexts (e.g., GuriRosenblit, 2009; Sáiz, 2009; Toon et al., 2009), which tend to produce narratives in tension with andragogical assumptions of adult students as being self-regulated almost by nature.

Furthermore, going back to Gravani's (2015) four distinctive characteristics of adults in distance learning, our findings suggest some similar arguments - such that one-size-fits-all principles do not work for this group of students with varied past experiences, needs, and interests. Nevertheless, our results also serve to challenge Gravani's pedagogical suggestions - such as that DE for adult students needs to be "more open, flexible, mutual, variable, active and autonomous" (ibid, p. 191). The adult students in this study would argue, by contrast i) that they need more support and structure for (rather than control over and flexibility in) their learning; ii) that, although having occasional opportunities to share their emotions with other students is perceived helpful, they find it more urgent to share (and learn) useful know-hows to be successful in their programs - direct relationships and interactions may not be necessary in this sharing practice, however; and iii) that having multiple pedagogical choices and options may simply be confusing and stressful. In fact, adult students in DE may want to be told exactly what to do and how to perform, especially at the beginning of their study. Subsequently, having set up specific study patterns based on that early input, then those students clearly want to remain in the same learning structure without the new lifestyle they have worked to established being interrupted by attempts to introduce further new or "flexible" structures.

However, while our findings, we hope, effectively question some of the andragogical assumptions about adult students in DE, this study also has its own limitations that need to be carefully reflected upon and used to guide our future research direction. First of all, this qualitative study heavily relies on a small number of participants' personal narratives - that is, students' subjective evaluation of their own learning experiences. Although we put reasonable effort into selecting the most information-rich group and including diverse voices within the selected group, by no means, would we wish to claim that our findings can be generalised to a wider adult population. 
Lee, K., Choi, H., \& Cho, Y. (in press). Becoming a competent self: A developmental process of adult distance learning. Internet and Higher Education. https://doi.org/10.1016/j.iheduc.2018.12.001

Instead, our focus is on providing useful insights into the experiences of successful adult distance learners in a specific DE context.

The validity of our findings should also be understood as having limitations derived from the reliance on students' memories in the construction of their accounts. Much of the narrative about participants' learning experiences in the early stages of their study, in particular, are drawn from their selected memories without having direct access to the real moments in the past. Some of the participants' learning journeys had lasted for about two decades (e.g., Participant A begun his journey in 1994 and Participant B in 1999). Given that the participants must have also gone through complex real-life situations and events while competing their study many years later; it may be also questioned if it is possible both for the participants to fully explain and for the researchers to fully understand such long journeys within one hour-long interviews. In this respect, our future research may employ a more longitudinal approach to investigating adult distance learning experiences: following, observing, and recording their developmental processes more closely over time.

We are also aware that this study is situated in a unique educational and cultural setting. KNOU has its own pedagogical historicity and contextual specificity (see Lee, 2018), which clearly implies that the distance learning experiences of adult students in this study can, by no means, be regarded as automatically representative of other adult students in different DE contexts. Nevertheless, we believe that this paper provides useful materials for reflection for those involved in similar practices in other settings, and we hope that this piece can foster further meaningful discussions within those settings.

The final limitation we wish to discuss is a conceptual issue. Throughout this study, we have put conscious effort into maintaining a focus on our central aim: re-evaluating the original andragogical claims that promote the adultness of adult learners and the static view of adult distance learning. This study, therefore, focuses on illustrating the developmental processes of adult students as they become self-regulated learners and, subsequently, (more) competent selves through their learning journey. That journey is far more dynamic and authentic than ones captured in much of the literature. However, it is important to note that the andragogical claims - the original distinctions between children and adult learners, in particular (e.g., Knowles, 1985) - have been long criticised by others in the boarder field of adult education (e.g., Edwards, 2008; Rachal, 2002; Sandlin, 2005). Subsequently, the development of adult learning "theories" has incorporated more nuanced and practical approaches to understanding how adults learn and how that learning might be supported. For example, as early as in 1991, Grow proposed the Staged Self-Directed Learning Model that illustrates appropriate teacher roles for each of the four stages of adult learners developing the self-directedness (i.e., being dependent, interested, involved, and self-directed). The model clearly highlights the importance of supporting the process of adult learners becoming self-regulated.

However, our effort to sharpen our arguments and remain focused inevitably leaves some of these valuable theoretical and practical discussions out of the scope of this paper. The exploratory nature of this study, nevertheless, suggests meaningful contributions to the further development of the previous achievements in at least two different ways. Firstly, the study findings suggest that most of the adult students entered KNOU with a lack of previous experiences, either in being a university student or in being a distance learner. The range of struggles, confusions, and uncertainties experienced by those adult students during their first semester strongly implies that when they started university-level study, they did not have a high level of academic locus of control, that is, self-regulation skills (in Lee, Choi, \& Kim, 2013). This study also clearly demonstrates that selfregulation skills can be developed during adult students' engagement with distance learning processes (even by trial-and-error on the part of the students themselves). This result, therefore, supports both Grow's (1991) and Cercone's (2008) proposals for more sophisticated support mechanisms for processes of adult learners becoming more self-regulated.

Secondly, it is noticeable that once the adult students have attained a sufficient degree of self-regulation, then subsequently they tend to remain relatively resilient and persistent, rather than being readily and negatively influenced by external conditions. Our participants stayed calm and carried on working on their study, even in quite challenging personal situations that involved a number of indicators usually associated with drop-out or 
Lee, K., Choi, H., \& Cho, Y. (in press). Becoming a competent self: A developmental process of adult distance learning. Internet and Higher Education. https://doi.org/10.1016/j.iheduc.2018.12.001

non-enrolment: a lack of time for study (Carnoy, et al., 2012), heavy workloads (Choi, et al., 2013), and other life obligations (Vergidis \& Panagiotakopoulos, 2002). Studying the narratives presented in this paper, therefore, adds new insights about the "next stages" after becoming self-directed (in Grow, 1991). That is, we can learn from our participants that they, after becoming self-regulated learners, clearly want to remain in a relatively consistent, stable, or predictable learning environment, in which their newly earned self-regulation skills are applicable. In addition, this study shows that the successful completion of the journey enables those adult learners to become competent selves and autonomous lifelong learners, which may be perceived as lifechanging by the students themselves. Thus, this study effectively expands the scope of those previous studies that have focused exclusively on the development of self-directedness. This can be considered an important theoretical contribution of our study.

All in all, we would like to emphasise that adult students' distance learning experiences can be developmental and transformative (rather than being pre-determined or instrumental). In this sense, we suggest that it is worthwhile for DE researchers and practitioners to examine adult learning more carefully and closely — outside of the andragogical views on adult learners' characteristics and abilities and the fixed division of adult students between completers and dropouts. 
Lee, K., Choi, H., \& Cho, Y. (in press). Becoming a competent self: A developmental process of adult distance learning. Internet and Higher Education. https://doi.org/10.1016/j.iheduc.2018.12.001

\section{Reference}

Allen, I. E., \& Seaman, J. (2015). Grade level. Tracking Online Education in the United States.

Brändle, T. (2016). How availability of capital affects the timing of enrollment: the routes to university of traditional and non-traditional students. Studies in Higher Education, 1-21.

Brookfield, S. (1986). Understanding and facilitating adult learning: A comprehensive analysis of principles and effective practices. McGraw-Hill Education.

Carnoy, M., Rabling, B. J., Castaño- Muñoz, J., Montoliu, J. M. D., \& Sancho- Vinuesa, T. (2012). Does On- line Distance Higher Education Pay Off for Adult Learners? The Case of the Open University of Catalonia. Higher Education Quarterly, 66(3), 248-271.

Castaño-Muñoz, J., Carnoy, M., \& Duart, J. M. (2016). Estimating the economic payoff to virtual university education: A case study of the Open University of Catalonia. Higher Education, 72(1), 1-24.

Castles, J. (2004). Persistence and the adult learner: factors affecting persistence in Open University students. Active learning in higher education, 5(2), 166-179.

Cercone, K. (2008). Characteristics of adult learners with implications for online learning design. AACE journal, 16(2), $137-$ 159.

Charmaz, K. (2014). Constructing Grounded Theory, Sage.

Choi, H., Lee, Y., Jung, I., \& Latchem, C. (2013). The extent of and reasons for non re-enrolment: A case of Korea National Open University. The International Review of Research in Open and Distributed Learning, 14(4).

Corbin, J., \& Strauss, A. (2014). Basics of Qualitative Research, Sage.

Gravani, M. N. (2015). Adult learning in a distance education context: theoretical and methodological challenges. International Journal of Lifelong Education, 34(2), 172-193.

Grow, G. O. (1991). Teaching learners to be self-directed. Adult education quarterly, 41(3), 125-149.

Guri-Rosenblit, S. (2009b).Challenges facing distance education in the $21^{\text {st }}$ century. In U. Bernath, A. Szücs, A. Tait, \& M.

Vidal (Eds.), Distance and e-learning in transition: Learning innovation, technology and social challenges (pp. 5-22). London, UK: ISTE Ltd.

Hashim, M. H. M., Hashim, Y., \& Esa, A. (2011). Online learning interaction continuum (OLIC): A qualitative case study. International Education Studies, 4(2), 18.

Hermans, H., Janssen, J., Vogten, H., \& Koper, R. (2015). Flexible Provisioning Adult Learners. J. UCS, 21(2), 206-222.

Ilgaz, H., \& Gülbahar, Y. (2015). A snapshot of online learners: E-readiness, e-satisfaction and expectations. International Review of Research in Open and Distributed Learning, 16(2), 171-187.

Jarvis, P. (2012). Towards a comprehensive theory of human learning. Routledge.

Joo, K. P. (2014a). A cultural-historical activity theory investigation of contradictions in open and distance higher education among alienated adult learners in Korea National Open University. The International Review of Research in Open and Distributed Learning, 15(1).

Joo, K. P. (2014b). Reconsidering Open and Distance Higher Education: A Life-History Analysis of Adult Learners in Korea National Open University. The Asia-Pacific Education Researcher, 23(3), 699-707.

Kember, D., \& Leung, D. Y. (2004). Relationship between the employment of coping mechanisms and a sense of belonging for part- time students. Educational Psychology, 24(3), 345-357.

Knowles, M. (1985). Andragogy in action. San Francisco, CA: Jossey-Bass.

Lee, Y., Choi, J., \& Kim, T. (2013). Discriminating factors between completers of and dropouts from online learning 
Lee, K., Choi, H., \& Cho, Y. (in press). Becoming a competent self: A developmental process of adult distance learning. Internet and Higher Education. https://doi.org/10.1016/j.iheduc.2018.12.001

courses. British Journal of Educational Technology, 44(2), 328-337.

Lee, Y., \& Choi, J. (2013). A structural equation model of predictors of online learning retention. The Internet and Higher Education, 16, 36-42.

Levy, Y. (2007). Comparing dropouts and persistence in e-learning courses. Computers \& Education, 48, 2, 185-204.

Lee, K. (2017). Rethinking the accessibility of online higher education: A historical review. The Internet and Higher Education. 33(1), 15-23

Makoe, M., Richardson, J. T., \& Price, L. (2008). Conceptions of learning in adult students embarking on distance education. Higher Education, 55(3), 303.

May, J., \& Bunn, R. J. (2015). 1974-1976: the seeds of longevity in a pathway to tertiary participation at University of Newcastle, NSW. Australian Journal of Adult Learning, 55(1), 135.

Merriam, S. B. (2001). Andragogy and self- directed learning: Pillars of adult learning theory. New directions for adult and continuing education, 2001(89), 3-14.

Mulenga, D., \& Liang, J. S. (2008). Motivations for older adults' participation in distance education: A study at the National Open University of Taiwan. International Journal of Lifelong Education, 27(3), 289-314.

Nair, G., \& Hindle, R. (2016). ICT in the Indian Classroom. In Human Development and Interaction in the Age of Ubiquitous Technology (pp. 73-93). IGI Global.

Raghavan, S., \& Kumar, P. R. (2007). The need for participation in open and distance education: The Open University Malaysia experience. Turkish Online Journal of Distance Education, 8(4).

Sáiz, F. B. (2009). Online learners' frustration: Implications for lifelong learning. In U. Bernath, A. Szücs, A. Tait, \& M. Vidal (Eds.), Distance and e-learning in transition: Learning innovation, technology and social challenges (pp. 519 528). London, UK: ISTE Ltd.

Strauss, A.L. and Corbin, J. (2015) Basics of Qualitative Research: Grounded Theory Procedures and Techniques, 4th edn. London: Sage.

Toon, A. J., Samir, A., Huang Mui Kheng, J., Kin Chew, L., Vythilingam, M., \& Low Wee Kiat, S. (2009). Blended teaching and learning in the School of Science and Technology of UniSIM. Interactive Technology and Smart Education, 6(4), 234-243.

Urquhart, C., 2013. Grounded theory for qualitative research : a practical guide, Sage.

Vergidis, D., \& Panagiotakopoulos, C. (2002). Student Dropout at the Hellenic Open University: Evaluation of the Graduate Program," Studies in Education". The International Review of Research in Open and Distributed Learning, 3(2). 